\title{
Impact of timing of ventriculoperitoneal shunt placement on outcome in posttraumatic hydrocephalus
}

\author{
Robert G. Kowalski, MBBCh, MS,, Alan H. Weintraub, MD,,33 Benjamin A. Rubin, MD, ${ }^{4}$ \\ Donald J. Gerber, PsyD, MEd, ABPP-rp, ${ }^{1}$ and Andrew J. Olsen, MD ${ }^{5}$
}

\begin{abstract}
${ }^{1}$ Research Department, Craig Hospital, Englewood, Colorado; '2Department of Neurology, University of Colorado School of Medicine, Aurora, Colorado; ${ }^{3} \mathrm{CNS}$ Medical Group; ${ }^{4}$ Colorado Brain \& Spine Institute; and ${ }^{5}$ Radiology Imaging Associates, Englewood, Colorado
\end{abstract}

OBJECTIVE Posttraumatic hydrocephalus (PTH) is a frequent sequela of traumatic brain injury (TBI) and complication
of related cranial surgery. The roles of PTH and the timing of cerebrospinal fluid (CSF) shunt placement in TBI outcome
have not been well described. The goal of this study was to assess the impact of hydrocephalus and timing of ventriculo-
peritoneal (VP) shunt placement on outcome during inpatient rehabilitation after TBI.
METHODS In this cohort study, all TBI patients admitted to Craig Hospital between 2009 and 2013 were evaluated for
PTH, defined as ventriculomegaly, and hydrocephalus symptoms, delayed or deteriorating recovery, or elevated opening
pressure on lumbar puncture. Extent of ventriculomegaly was quantified by the Evans index from CT scans. Outcome
measures were emergence from and duration of posttraumatic amnesia (PTA) and functional status as assessed by
means of the Functional Independence Measure (FIM). Findings in this group were compared to findings in a group of
TBI patients without PTH (controls) who were admitted for inpatient rehabilitation during the same study period and met
specific criteria for inclusion.

RESULTS A total of 701 patients were admitted with TBI during the study period. Of these patients, 59 (8\%) were diagnosed with PTH and were included in this study as the PTH group, and 204 who were admitted for rehabilitation and met the criteria for inclusion as controls constituted the comparison group (no-PTH group). PTH was associated with initial postinjury failure to follow commands, midline shift or cistern compression, subcortical contusion, and craniotomy or craniectomy. In multivariable analyses, independent predictors of longer PTA duration and lower FIM score at rehabilitation discharge were PTH, emergency department Glasgow Coma Scale motor score $<6$, and longer time from injury to rehabilitation admission. PTH accounted for a 51-day increase in PTA duration and a 29-point reduction in discharge FIM score. In $40 \%$ of PTH patients with preshunt CT brain imaging analyzed, ventriculomegaly (Evans index $>0.3$ ) was observed 3 or more days before VP shunt placement (median 10 days, range 3-102 days). Among PTH patients who received a VP shunt, earlier placement was associated with better outcome by all measures assessed and independently predicted better FIM total score and shorter PTA duration.

CONCLUSIONS Posttraumatic hydrocephalus predicts worse outcome during inpatient rehabilitation, with poorer functional outcomes and longer duration of PTA. In shunt-treated PTH patients, earlier CSF shunting predicted improved recovery. These results suggest that clinical vigilance for $\mathrm{PTH}$ onset and additional studies on timing of CSF diversion are warranted.

https://thejns.org/doi/abs/10.3171/2017.7.JNS17555

KEY WORDS posttraumatic hydrocephalus; traumatic brain injury; ventriculoperitoneal shunt

$\mathrm{P}$ OSTTRAUMATIC hydrocephalus (PTH) is an excess accumulation of intracranial cerebrospinal fluid (CSF) following traumatic brain injury (TBI). The incidence of PTH in patients who have suffered TBI has been reported to be as high as $51 \%$., $, 11,28,35$ PTH characteristically involves ventriculomegaly identifiable on brain imaging. As with other hydrocephalus types, this finding is not pathognomonic, as enlarged ventricles may result

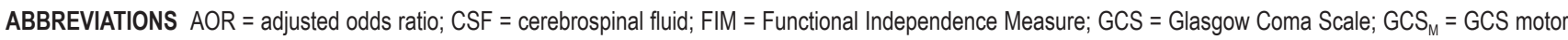
score; ICP = intracranial pressure; IVH = intraventricular hemorrhage; PTA = posttraumatic amnesia; $\mathrm{PTH}=$ posttraumatic hydrocephalus; $\mathrm{SAH}=$ subarachnoid hemorrhage; $\mathrm{TBI}=$ traumatic brain injury; TBIMS = Traumatic Brain Injury Model Systems; VP = ventriculoperitoneal.

SUBMITTED March 3, 2017. ACCEPTED July 24, 2017.

INCLUDE WHEN CITING Published online February 23, 2018; DOI: 10.3171/2017.7.JNS17555. 
from parenchymal atrophy associated with factors such as increased age, infection, or Wallerian degeneration of damaged neurons in traumatic injury to the brain. .,, $30^{3}$

Clinical signs and symptoms of PTH, in addition to enlarged ventricles, may include papilledema or seizures when intracranial pressure (ICP) is elevated ${ }^{9}$ and clinical status that slows or deteriorates during the subacute recovery phase of TBI. ${ }^{18,25}$ Clinical presentation in PTH may differ significantly from that seen in other hydrocephalus types. It may not involve increased ICP, as often accompanies congenital and noncommunicating hydrocephalus. ${ }^{40}$ Nor is PTH necessarily associated with the gait abnormalities, urinary incontinence, or dementia observed in normal pressure hydrocephalus. ${ }^{18,37}$

The mechanism of injury leading to PTH may be obstructive, involving disruption of normal CSF circulation by TBI-related intraventricular hemorrhage (IVH), subarachnoid hemorrhage (SAH), or space-occupying lesions with associated mass effect. PTH may also stem from a nonobstructive phenomenon that involves alteration of CSF flow dynamics due to disturbance of CSF reabsorption at arachnoid granulations and physiological changes in intracranial venous outflow and pulsatility.,27,38

Furthermore, PTH often arises after decompressive craniotomy or craniectomy performed to help relieve suspected elevated ICP related to TBI and restore normal perfusion. ${ }^{6,8,14}$ Some authors have suggested that PTH may be caused by alteration of CSF flow dynamics resulting from these surgeries..$^{24,39}$

With the heterogeneity of PTH presentation and the subjectivity of clinical judgment in evaluating relevant signs, a standardized definition for the diagnosis remains elusive. Nonetheless, the etiology of hydrocephalus following TBI has been explored in a limited number of studies, which identified increased age, injury severity, presence and degree of IVH and SAH, decompressive cranial surgery, and persisting lower level of consciousness as possible risk factors. ${ }^{17,18}$ To date, however, the outcome for patients with suspected PTH following TBI has received relatively little research focus. This is particularly true regarding timing of PTH onset and shunt placement.

In light of this research void, we sought to assess predictors of onset of hydrocephalus in patients with moderate to severe TBI receiving inpatient rehabilitation and to assess its impact on outcome relative to other factors, including patient characteristics, injury severity, and other types of neuroanatomical derangement. We also sought to assess the effect of the timing of PTH onset and its treatment with CSF shunting on outcome. Given known potential mechanisms of hydrocephalus onset following brain trauma, we hypothesized that structural derangements to brain architecture resulting from TBI that impede CSF flow, particularly those producing mass effect or impairing reabsorption, are associated with PTH onset. We further hypothesized that incidence of hydrocephalus following TBI is a surrogate marker of greater initial severity of brain insult and associated with prolonged recovery and poorer functional and cognitive outcome.

\section{Methods}

This study is a retrospective comparative analysis of outcome between patients with and without evidence of PTH who were admitted to Craig Hospital, Rocky Mountain Regional Brain Injury System, from January 1, 2009, to December 31, 2013, with a diagnosis of TBI. The study was approved by the hospital's institutional review board and privacy board.

\section{PTH Group}

All TBI patients admitted during the study period were evaluated for PTH, recorded in the electronic medical record by International Classification of Diseases, Ninth Revision (ICD-9) code, and further defined for this study as radiographic evidence of ventriculomegaly disproportionate to patient age and one or more of the following: hydrocephalus symptoms, including gait disturbance or urinary incontinence; functional and cognitive recovery at a clinical plateau, delayed, or deteriorating to a degree discordant with injury severity; and/or elevated opening pressure on lumbar puncture. All patients who met these criteria were included in the PTH group.

\section{No-PTH Group}

Controls were selected from patients with moderate to severe TBI without hydrocephalus who were admitted for inpatient rehabilitation during the same study period and were also enrolled in the hospital's Traumatic Brain Injury Model Systems (TBIMS) National Database study. Criteria for inclusion in the TBIMS study include age $\geq$ 16 years at injury, presentation to an acute hospital within 72 hours of injury, and at least one of the following: posttraumatic amnesia (PTA) of more than 24 hours' duration, trauma-related intracranial abnormalities identified on neuroimaging, loss of consciousness of more than $30 \mathrm{~min}$ utes' duration, or a Glasgow Coma Scale (GCS) score $<13$ at initial emergency department presentation. All patients who met these criteria and had available CT imaging and GCS motor scores $\left(\mathrm{GCS}_{\mathrm{M}}\right)$ from initial hospital presentation following injury were included in the study analysis.

\section{Procedures}

Demographics, mechanism of brain injury, and clinical status at the time of acute hospitalization and during inpatient rehabilitation were recorded for all study patients. Baseline clinical characteristics included GCS score at presentation, presence or absence of PTA, type of injury, and days from injury to inpatient rehabilitation admission. Hospital procedure variables included craniotomy, craniectomy, ICP monitor placement, and CSF drainage. The timing of ventriculoperitoneal (VP) shunt placement and shunt-related complications were recorded from the electronic medical record. The study outcome measures were functional status as assessed by means of the Functional Independence Measure (FIM) scale, ${ }^{31}$ emergence and duration of PTA, and rehabilitation length of stay. Patients were assessed with the FIM at the time of inpatient rehabilitation admission and discharge. PTA was assessed with the Galveston Orientation and Amnesia Test (GOAT) ${ }^{23}$ or the Orientation Log $(\mathrm{O}-\mathrm{Log}){ }^{16}$ PTA duration was abstracted from the acute hospitalization medical record or the rehabilitation medical record. PTA was recorded as a 
dichotomous variable (emergence vs no emergence prior to discharge from inpatient rehabilitation) and as a continuous variable (duration of amnesia in days). For patients who did not emerge from PTA, duration was recorded as number of days from injury to rehabilitation discharge.

\section{Ventriculomegaly Characterization}

Extent of ventricular enlargement was quantified for patients with PTH by calculating the Evans index from available CT scans obtained clinically. This included the first scan available after injury for all PTH patients, and pre-shunt placement imaging for those who received a VP shunt. The Evans index was calculated as the ratio of the transverse diameter of the anterior horns of the lateral ventricles to the largest internal diameter of the skull. ${ }^{33,36}$ Measurements were made by a rater with specialty training in neurology (R.G.K.).

\section{Interrater Reliability Analysis}

A second Evans index calculation was performed independently for scans of $36(61 \%)$ of the PTH patients by a board-certified neuroradiologist (A.J.O.) who was blinded to the patients' clinical status. The raters were blinded to each other's scores. Ventriculomegaly was defined as an Evans index $>0.30 .^{15,34}$ Agreement between raters was determined with the unweighted Cohen kappa statistic. ${ }^{20}$ CT scans were selected randomly for the interrater reliability analysis. Utilizing an alpha rate of 0.05 and a beta error rate of 0.2 , testing for a statistical difference between moderate (0.50) and high (0.80) unweighted Cohen kappa values, sample size estimates for the interrater reliability analysis ranged from 17 to 35 when the proportion of positive findings for PTH was between $10 \%$ and $70 \% .{ }^{32}$ Measurements made by the primary rater (R.G.K.) were used in the study analysis, which was undertaken after all radiology ratings were completed.

\section{Additional Neuroimaging Characteristics}

Neuroanatomical characteristics following TBI were recorded for study patients from available CT and MRI studies. For patients with PTH, relevant neuroanatomical findings, including evidence of mass effect (midline shift, compression of basal cisterns), contusion (cortical, subcortical), and hemorrhage (IVH, SAH, subdural hematoma), were obtained from neuroradiology reports for brain scans obtained clinically during acute hospitalization and inpatient rehabilitation. For controls (the no-PTH group), CT observations were recorded from neuroradiology reports following modified Marshall CT classification criteria ${ }^{21}$ used in the TBIMS Database methodology, including only the most abnormal findings in the initial 7 days following injury onset.

\section{Statistical Analysis}

For main study analyses, patients were dichotomized into those with PTH versus those without PTH. Clinical characteristics and outcome measurements were treated as continuous or categorical variables, as appropriate, and were dichotomized based on clinically relevant cut points.

Dichotomous variables were analyzed with the Pearson chi-square test or Fisher's exact test where appropriate. Continuous variables were analyzed with the independent samples Student t-test (2-tailed) when normally distributed. For categorical variables and those not normally distributed, nonparametric tests (Mann-Whitney U-test and Kruskal-Wallis test) were used. Independent predictors of PTH onset and outcome were identified with backward multivariable linear regression for continuous outcome variables, and backward stepwise logistic regression for dichotomous outcome variables. Factors found to be associated with PTH onset and outcome in univariate analyses $(p<0.05)$ were incorporated in these multivariable models.

\section{Subgroup Analyses}

A separate analysis was carried out in a subgroup of only those patients who received CSF diversion to assess the role of PTH onset and CSF shunting on outcome. Separate analyses also were carried out in a subset of only those patients with a $\mathrm{GCS}_{\mathrm{M}}$ less than 6 (failure to follow commands) at emergency department presentation, to control for injury severity; in a subset of only those patients with a $\mathrm{GCS}_{\mathrm{M}}$ of 6 (following commands) at emergency department presentation, to evaluate factors leading to PTH among patients with good initial clinical status; and in a subset of only those patients who underwent craniotomy or craniectomy following injury, to account for potential surgical source of PTH onset. To further address potential baseline differences between PTH patients and controls, analyses were repeated in a separate subset of patients in which those with PTH were matched in a 1:1 ratio with controls using propensity score matching ${ }^{2}$ to control for age, sex, year of injury, and days from injury to admission to inpatient rehabilitation. Significance was set at $\mathrm{p}<0.05$. Data were analyzed with IBM SPSS version 22.0 (IBM Corp.).

\section{Results}

Between 2009 and 2013, 701 patients admitted to Craig Hospital with a primary diagnosis of TBI were evaluated for inclusion in the study. A total of 263 patients met the study criteria and were included in the analysis; 59 of these patients were diagnosed with PTH, and 204 were included as controls (no-PTH group). Of the 263 included patients, $193(73 \%)$ were male. The patients' median age was 30 years (range 16-74 years), and the most common cause of TBI was motor vehicle or bicycle collision (54\%), followed by fall (24\%) and sports-related head impact (11\%) (Table 1).

\section{Overall TBI Study Population: Comparison of Patient Characteristics in the PTH and No-PTH Groups}

No significant differences were observed between patients with PTH and non-PTH controls with respect to demographic characteristics or injury type. At initial emergency department presentation following injury, patients who developed PTH were less likely to follow commands $\left(\mathrm{GCS}_{\mathrm{M}}<6\right)$ than those who did not develop PTH $\left(\mathrm{GCS}_{\mathrm{M}}<6\right.$ in $12 \%$ of the PTH group vs $38 \%$ of the nonPTH group, $\mathrm{p}<0.001)$. 


\section{Imaging}

Interrater Variability

In a sample of brain CT scans for $36 \mathrm{PTH}$ patients (representing $61 \%$ of PTH cases), the rate of absolute agreement between raters (R.G.K. and A.J.O.) regarding the presence of ventriculomegaly (Evans index $>0.30$ ) was $100 \%$. Agreement between raters on the actual Evans index extrapolated to 2 decimal places was substantial. The kappa coefficient for Evans index \pm 0.02 was $0.762(95 \%$ CI 0.548-0.976).

\section{Ventriculomegaly}

Among all patients with PTH, the median Evans index based on the first CT brain scan available after injury was 0.33 (range 0.13-0.57). Among PTH patients who received a VP shunt and who had CT scans obtained prior to shunt placement and available in the electronic medical record $(\mathrm{n}=27)$, the median Evans index was 0.38 (range $0.25-0.51$ ). Of these 27 patients, $93 \%$ had evidence of ventriculomegaly (Evans index $>0.3$ ) on these CT scans. These findings were observed a median of 1 day (range 0-178 days) prior to shunt placement. In $60 \%$ of the patients with ventriculomegaly (Evans index $>0.3$ ) observed on available preshunting CT brain imaging, VP shunt placement occurred within 2 days of this finding, while for the remaining $40 \%$, shunt placement occurred $\geq 3$ days later (median 10 days, range 3-102 days).

\section{Other Neuroradiological and Clinical Characteristics}

PTH patients were more likely to have radiographic evidence of intracranial mass effect, with midline shift or compression of basal cisterns (present in $83 \%$ of PTH group vs $35 \%$ of no-PTH group, $\mathrm{p}<0.001$ ); were more likely to have cortical contusions (evident in $97 \%$ of PTH group vs $78 \%$ of no-PTH group, $\mathrm{p}=0.001$ ); and more frequently had evidence of contusions in subcortical white matter (present in $32 \%$ of PTH group vs $12 \%$ of no-PTH group, $\mathrm{p}<0.001)$. Patients who developed hydrocephalus more often underwent craniotomy or craniectomy (64\% of PTH group vs $23 \%$ of no-PTH group, $\mathrm{p}<0.001$ ) and had longer acute hospitalization following injury (median 67 days in the PTH group vs 16 days in the no-PTH group, $p$ $<0.001)$ (Table 2).

\section{Predictors of PTH Onset}

Predictors of PTH development included poorer initial clinical status $\left(\mathrm{GCS}_{\mathrm{M}}<6\right)$ on initial presentation to the emergency department immediately after injury (adjusted odds ratio [AOR] 3.071, 95\% CI 1.221-7.724, $\mathrm{p}<$ 0.017 ); evidence of intracranial mass effect, with midline shift or compression of basal cisterns (AOR 4.505, 95\% CI 1.830-11.091, $\mathrm{p}<0.001$ ); subcortical contusion (AOR $2.947,95 \%$ CI $1.274-6.818, \mathrm{p}=0.012$ ); and craniotomy or craniectomy (AOR 3.056, 95\% CI 1.357-6.880, $\mathrm{p}=0.007$ ) (Table 3). Of the patients who were following commands at initial emergency department presentation $\left(\mathrm{GCS}_{\mathrm{M}}=6\right)$, $8 \%(\mathrm{n}=7)$ went on to develop PTH. The patients in this subgroup with PTH had longer acute hospitalization than those who did not develop PTH (median 54 days in subgroup with PTH vs 12 days in subgroup without PTH, p
TABLE 1. Characteristics of study population

\begin{tabular}{|c|c|}
\hline Characteristic & Value \\
\hline No. of pts & 263 \\
\hline \multicolumn{2}{|l|}{ Demographic characteristics } \\
\hline Age at injury in yrs, median & $30(16-74)$ \\
\hline Sex: male & $193(73)$ \\
\hline \multicolumn{2}{|l|}{ TBI etiology } \\
\hline Vehicle collision & $143(54)$ \\
\hline Sports & $29(11)$ \\
\hline Fall & $63(24)$ \\
\hline Violence & $12(5)$ \\
\hline Other & $16(6)$ \\
\hline \multicolumn{2}{|l|}{ Clinical characteristics } \\
\hline $\mathrm{GCS}_{\mathrm{M}}<6^{*}$ & $178(68)$ \\
\hline Days from injury to rehab admission, median & $23(3-309)$ \\
\hline \multicolumn{2}{|l|}{ Neuroanatomic characteristics of injury } \\
\hline Midline shift or cistern compression & $119(45)$ \\
\hline Punctate/petechial hemorrhage & $115(44)$ \\
\hline IVH & $72(27)$ \\
\hline SAH or subdural fluid collection & $225(86)$ \\
\hline Epidural hematoma & $48(18)$ \\
\hline Cortical contusion & $216(82)$ \\
\hline Subcortical white matter contusion & $44(17)$ \\
\hline Intraparenchymal bone fragments & $14(5)$ \\
\hline
\end{tabular}

$<0.001$ ), were more likely to have midline shift or cistern compression (present in $71 \%$ of the subgroup with PTH vs $31 \%$ of the subgroup without PTH, p = 0.045), and were more likely to have undergone craniotomy or craniectomy (71\% of the subgroup with PTH vs $22 \%$ of the subgroup without PTH, $\mathrm{p}=0.011$ ) (Supplemental Table 1).

\section{Associations Between PTH Incidence and Outcome}

In univariate analyses, patients who developed PTH had worse outcomes by all study outcome measures than those who did not. Patients with PTH were less likely to emerge from PTA by the time of inpatient rehabilitation discharge (61\% of the PTH group vs $92 \%$ of the no-PTH group, $\mathrm{p}<0.001$ ), and for those who did emerge, length of PTA was longer (median 122 days for patients who did emerge from PTA in the PTH group vs 15 days in the no-PTH group, $\mathrm{p}<0.001)$. The total FIM score was lower for PTH patients at the time of rehabilitation admission (median 20 in the PTH group vs 55 in the no-PTH group, $\mathrm{p}<0.001)$ and at rehabilitation discharge (median 43 in the PTH group vs 114 in the no-PTH group, $\mathrm{p}<0.001$ ); the degree of change in total FIM score during rehabilitation was also lower in the PTH group (median +13 in the PTH group vs +48 in the no-PTH group, $\mathrm{p}<0.001$ ). The inpatient rehabilitation length of stay was longer for PTH patients (median 88 days for patients in the PTH group vs 39 days for those in the no-PTH group, $\mathrm{p}<0.001$ ) (Table 4). 
TABLE 2. Comparison of patient characteristics and PTH

\begin{tabular}{|c|c|c|c|}
\hline Characteristic & PTH $(n=59)$ & No PTH $(n=204)$ & $\mathrm{p}$ Value \\
\hline \multicolumn{4}{|l|}{ Demographic characteristics } \\
\hline Age at injury in yrs, median & $25(16-74)$ & $31(16-74)$ & NS \\
\hline Sex: male & $43(73)$ & $150(73)$ & NS \\
\hline TBI etiology & & & NS \\
\hline Vehicle collision & $37(63)$ & $106(52)$ & \\
\hline Sports & $5(8)$ & $24(12)$ & \\
\hline Fall & $13(22)$ & $50(24)$ & \\
\hline Violence & $3(5)$ & $9(4)$ & \\
\hline Other & $1(2)$ & $15(7)$ & \\
\hline \multicolumn{4}{|l|}{ Clinical characteristics } \\
\hline $\mathrm{GCS}_{\mathrm{M}}<6$ & $52(88)$ & $126(62)$ & $<0.001$ \\
\hline Days from injury to rehab admission, median & $67(19-309)$ & $16(3-140)$ & $<0.001$ \\
\hline \multicolumn{4}{|l|}{ Neuroanatomic characteristics of injury } \\
\hline Midline shift or cistern compression & $49(83)$ & $70(35)$ & $<0.001$ \\
\hline Punctate/petechial hemorrhage & $29(49)$ & $86(42)$ & NS \\
\hline IVH & $18(30)$ & $54(26)$ & NS \\
\hline SAH or subdural fluid collection & $55(93)$ & $170(83)$ & 0.057 \\
\hline Epidural hematoma & $12(20)$ & $36(18)$ & NS \\
\hline Cortical contusion & $57(97)$ & $159(78)$ & 0.001 \\
\hline Subcortical white matter contusion & $19(32)$ & $25(12)$ & $<0.001$ \\
\hline Intraparenchymal bone fragments & $5(8)$ & $9(4)$ & NS \\
\hline \multicolumn{4}{|l|}{ Hospital course } \\
\hline Craniotomy & $13(22)$ & $26(13)$ & 0.080 \\
\hline Craniectomy & $30(51)$ & $25(12)$ & $<0.001$ \\
\hline Craniotomy or craniectomy & $38(64)$ & $46(23)$ & $<0.001$ \\
\hline
\end{tabular}

NS $=$ not statistically significant and $p>0.100$.

Data presented as number (\%) unless otherwise indicated. Medians are presented with ranges.

Among the subset of patients who were following commands at initial emergency department presentation, outcomes were worse for those patients who developed PTH, with a longer duration of PTA (median 72 days for patients with PTH vs 6 days for those without PTH, $\mathrm{p}<0.001$ ) and lower FIM total score at the time of rehabilitation discharge (median 69 for patients with PTH vs 116 for those without PTH, p < 0.001) (Supplemental Table 2). Associations between PTH and study outcome measures were similar in a subset of patients that included only those with poor clinical status $\left(\mathrm{GCS}_{\mathrm{M}}<6\right)$ at initial emergency department presentation following injury (Supplemental Table 3) and a subset that included only those who underwent craniotomy or craniectomy procedures (Supplemental Table 4), as well as in a comparison with PTH patients matched to non-PTH controls through propensity scores (Supplemental Table 5).

\section{Predictors of Outcome}

In multivariable analysis utilizing logistic regression, predictors of emergence from PTA prior to discharge from inpatient rehabilitation included better clinical status $\left(\mathrm{GCS}_{\mathrm{M}}=6\right.$, or able to follow commands) at the time of initial emergency department presentation (AOR $16.149,95 \%$ CI 2.138-121.963, $\mathrm{p}=0.007)$ and absence of PTH (AOR 5.235, 95\% CI 2.463-11.111, p < 0.001) (Table 5).

In multivariable analyses utilizing linear regression, predictors of longer PTA among all patients in the study were poorer clinical status $\left(\mathrm{GCS}_{\mathrm{M}}<6\right.$, failure to follow commands) on initial presentation after injury, longer acute hospitalization, and PTH. Failure to follow commands on initial presentation accounted for 16.9 days of PTA duration (95\% CI 6.8-27.1 days, $\mathrm{p}=0.001)$, PTH accounted for 51.5 days of PTA duration (95\% CI 37.6-65.4

TABLE 3. Predictors of PTH onset in 263 patients: results of multivariable logistic regression

\begin{tabular}{lccc}
\hline \multicolumn{1}{c}{ Predictor } & AOR & p Value & \multicolumn{2}{c}{$95 \% \mathrm{Cl}$} \\
\hline Age at injury in yrs & \multicolumn{3}{c}{ NS } \\
\hline Sex: male & \multicolumn{3}{c}{ NS } \\
\hline GCS $_{M}<6$ & 3.071 & 0.017 & $1.221-7.724$ \\
\hline Midline shift or cistern compression & 4.505 & 0.001 & $1.830-11.091$ \\
\hline SAH or subdural fluid collection & \multicolumn{3}{c}{ NS } \\
\hline Cortical contusion & \multicolumn{3}{c}{ NS } \\
\hline Subcortical contusion & 2.947 & 0.012 & $1.274-6.818$ \\
\hline Craniotomy or craniectomy & 3.056 & 0.007 & $1.357-6.880$ \\
\hline
\end{tabular}


TABLE 4. Univariate comparison of outcome for patients with and without PTH

\begin{tabular}{|c|c|c|}
\hline Outcome Measure & $\begin{array}{c}\text { PTH } \\
(n=59)\end{array}$ & $\begin{array}{l}\text { No PTH } \\
(n=204)\end{array}$ \\
\hline \multicolumn{3}{|l|}{ PTA } \\
\hline Emergence from PTA, n (\%) & $36(61)$ & $182(92)$ \\
\hline Duration of PTA in days, ${ }^{*}$ all pts & $138(45-401)$ & $19(0-229)$ \\
\hline $\begin{array}{l}\text { Duration of PTA in days, } \\
\text { emerged only }\end{array}$ & $122(45-319)$ & $15(0-159)$ \\
\hline \multicolumn{3}{|l|}{ Admission FIM } \\
\hline Motor score & $13(13-54)$ & $44(13-79)$ \\
\hline Cognitive score & $7(5-22)$ & $15(5-28)$ \\
\hline Total score & $20(18-76)$ & $55(18-105)$ \\
\hline \multicolumn{3}{|l|}{ Discharge FIM } \\
\hline Motor score & $26(13-86)$ & $86(13-91)$ \\
\hline Cognitive score & $13(5-33)$ & $27(5-35)$ \\
\hline Total score & $43(18-118)$ & $114(18-125)$ \\
\hline \multicolumn{3}{|l|}{$\Delta \mathrm{FIM}$ (during rehab)† } \\
\hline Motor score & $+10(-27$ to +65$)$ & $+38(-5$ to +71$)$ \\
\hline Cognitive score & $+5(-14$ to +21$)$ & $+10(-4$ to +23$)$ \\
\hline Total score & $+13(-41$ to +86$)$ & $+48(-5$ to +92$)$ \\
\hline Rehab LOS in days & $88(10-190)$ & $39(1-146)$ \\
\hline
\end{tabular}

LOS = length of stay.

Data presented as median (range) unless otherwise indicated. The betweengroups difference was statistically significant $(p<0.001)$ for all univariate comparisons.

* Days from injury to rehabilitation discharge if no emergence from PTA.

$\dagger$ Change in FIM between rehabilitation admission and discharge.

days, $\mathrm{p}<0.001$ ), and days in acute hospitalization accounted for 1.1 days of PTA duration (95\% CI 0.9-1.2 days, $\mathrm{p}<$ 0.01) (Table 6).

Better initial clinical status $\left(\mathrm{GCS}_{\mathrm{M}}=6\right.$, following commands) was a predictor of higher FIM total score at the time of rehabilitation, while longer acute hospitalization and hydrocephalus predicted poorer FIM total score. Following commands at initial presentation accounted for an 8.5-point increase in FIM total score at rehabilitation discharge (95\% CI 2.6-14.5, $\mathrm{p}=0.005)$, and presence of hydrocephalus accounted for a 28.9-point decrease in FIM total score $(95 \%$ CI -20.8 to $-37.1, \mathrm{p}<0.001)$.

\section{Patients With VP Shunt Diversion of CSF}

\section{Patient Characteristics}

Of the 59 patients diagnosed with PTH after brain injury, $52(88 \%)$ received a VP shunt prior to discharge from inpatient rehabilitation, and this was placed during the acute hospitalization in 23 (44\%) of these patients. The median time from injury to shunt placement was 69 days (range 9-366 days).

\section{Comparison of Patient Characteristics and Timing of Shunt Placement}

For purposes of analysis, timing of shunt placement was dichotomized as earlier ( $\leq 69$ days from injury onset) or later (> 69 days from injury onset). Demographic char-
TABLE 5. Predictors of PTA emergence in 263 TBI patients: results of multivariable logistic regression

\begin{tabular}{lccc}
\hline \multicolumn{1}{c}{ Predictor } & AOR & p Value & $95 \% \mathrm{Cl}$ \\
\hline $\mathrm{GCS}_{\mathrm{M}}=6^{*}$ & 16.149 & 0.007 & $2.138-121.963$ \\
\hline Absence of hydrocephalus & 5.235 & $<0.001$ & $2.463-11.111$ \\
\hline Midline shift or compression & & $\mathrm{NS}$ & \\
\hline IVH & & $\mathrm{NS}$ & \\
\hline Craniotomy or craniectomy & & $\mathrm{NS}$ & \\
\hline Subcortical contusion & & $\mathrm{NS}$ & \\
\hline * Following commands. & & &
\end{tabular}

acteristics and clinical status at initial emergency department presentation were similar for patients who underwent VP shunt placement earlier versus later. No difference was observed with respect to the frequency of intracranial hemorrhage (IVH, SAH, subdural fluid collection), cortical contusions, or midline shift or cistern compression in earlier versus later shunting subgroups. Patients who had a shunt placed earlier were more likely to have had an epidural fluid collection (35\% vs $9 \%$ in the later shunt placement subgroup, $\mathrm{p}=0.017$ ), while patients who had a shunt placed later were more likely to have radiographic evidence of subcortical white matter contusion $(46 \%$ vs $15 \%$ in the earlier shunt placement subgroup, $\mathrm{p}=0.016$ ) (Table 7).

\section{Associations Between Timing of VP Shunt Placement and Outcome}

Earlier shunt timing ( $\leq 69$ days) was not associated with frequency of emergence from PTA by the time of rehabilitation discharge. Earlier VP shunt placement was associated with better outcome on all other measures assessed at discharge (Figs. 1 and 2). Duration of PTA was shorter for those who had shunts placed earlier (median 122 days vs 179 days for those who had shunts placed later, $p<0.001$ ), discharge FIM total score was higher (median 59 vs 30 in the shunt placement subgroup, $\mathrm{p}=0.003$ ), and rehabilitation length of stay was shorter (median 69.5 days vs 109 days in the later shunt placement subgroup, $\mathrm{p}<0.001$ ) (Table 8).

\section{Predictors of Outcome in Shunt-Treated Patients}

When compared with initial clinical status, age, presence of intracranial mass effect, and intracranial surgery, earlier placement of a VP shunt independently predicted better outcome in patients with PTH. Later shunt placement accounted for a 24.2-point decrease in FIM total score $(95 \% \mathrm{CI}-38.8$ to $-9.5, \mathrm{p}=0.002)$ and for 67.7 days of PTA duration (95\% CI 27.1-108.3 days, $\mathrm{p}=0.002$ ) (Table 9).

\section{Discussion}

During the 5-year period of this study, 59 (8\%) of patients admitted for inpatient rehabilitation for TBI at our center were diagnosed with PTH. This is consistent with the range $(0.7 \%-51 \%)$ of PTH frequency reported in previous studies. ${ }^{11,35}$ Patients with PTH were comparable in age, 
TABLE 6. Predictors of outcome at time of inpatient rehabilitation in 263 patients: results of multivariable logistic regression

\begin{tabular}{|c|c|c|c|c|c|c|}
\hline Outcome \& Predictors & Unstandardized $\beta$ & SE & Standardized $\beta$ & $p$ Value & $95 \% \mathrm{Cl}$ for $\beta$ & Adjusted $\mathrm{R}^{2}$ \\
\hline Rehab admission FIM total score & & & & & & 0.413 \\
\hline (Constant) & 51.287 & 2.313 & & $<0.001$ & $46.728-55.846$ & \\
\hline $\mathrm{GCS}_{\mathrm{M}}=6$ & 16.706 & 2.944 & 0.320 & $<0.001$ & $10.902-22.509$ & \\
\hline Days from injury to rehab admission & -0.106 & 0.034 & -0.216 & 0.002 & -0.172 to -0.040 & \\
\hline PTH & -15.043 & 3.535 & -0.292 & $<0.001$ & -22.011 to -8.075 & \\
\hline Midline shift or cistern compression & -4.158 & 3.177 & -0.090 & 0.192 & -10.420 to 2.105 & \\
\hline Subcortical injury & -2.036 & 3.194 & -0.035 & 0.525 & -8.332 to 4.261 & \\
\hline Craniotomy or craniectomy & 2.257 & 3.414 & 0.046 & 0.509 & -4.473 to 8.986 & \\
\hline Rehab discharge FIM total score & & & & & & 0.622 \\
\hline (Constant) & 109.742 & 2.485 & & $<0.001$ & $104.848-114.636$ & \\
\hline $\mathrm{GCS}_{\mathrm{M}}=6$ & 8.538 & 3.035 & 0.117 & 0.005 & $2.561-14.515$ & \\
\hline Days from injury to rehab admission & -0.351 & 0.039 & -0.455 & $<0.001$ & -0.429 to -0.273 & \\
\hline PTH & -28.950 & 4.162 & -0.355 & $<0.001$ & -37.147 to -20.753 & \\
\hline Midline shift or cistern compression & -0.993 & 3.436 & -0.014 & 0.773 & -7.760 to 5.775 & \\
\hline Subcortical injury & -6.338 & 3.712 & -0.070 & 0.089 & -13.649 to 0.972 & \\
\hline Craniotomy or craniectomy & 1.665 & 3.701 & 0.023 & 0.653 & -5.625 to 8.954 & \\
\hline Duration of PTA in days* & & & & & & 0.784 \\
\hline (Constant) & 14.552 & 4.229 & & 0.001 & $6.222-22.881$ & \\
\hline $\mathrm{GCS}_{\mathrm{M}}<6$ & 16.947 & 5.148 & -0.105 & 0.001 & $6.809-27.086$ & \\
\hline Days from injury to rehab admission & 1.073 & 0.067 & 0.631 & $<0.001$ & $0.941-1.204$ & \\
\hline PTH & 51.495 & 7.044 & 0.287 & $<0.001$ & $37.621-65.368$ & \\
\hline Midline shift or cistern compression & 5.450 & 5.777 & 0.036 & 0.346 & -5.928 to 16.828 & \\
\hline Subcortical injury & 12.040 & 6.281 & 0.060 & 0.056 & -0.330 to 24.410 & \\
\hline Craniotomy or craniectomy & -11.571 & 6.195 & -0.071 & 0.063 & -23.772 to 0.631 & \\
\hline
\end{tabular}

* Days from injury to rehabilitation discharge if no emergence from PTA.

sex, and injury type with a group of 204 patients admitted with TBI during the same period who did not develop hydrocephalus.

Independent predictors of PTH onset included poorer clinical status at initial presentation $\left(\mathrm{GCS}_{\mathrm{M}}<6\right.$, failure to follow commands), presence of midline shift or compression of basal cisterns, contusion in the subcortical white matter, and decompressive cranial surgery (craniotomy or craniectomy). These findings complement previous reports, which found that intracranial hemorrhage, persistent disordered consciousness, and initial poor clinical status were risk factors for development of PTH. ${ }^{5,10}$ One recent report found an association between older age and PTH onset. ${ }^{18}$ Age did not predict hydrocephalus onset in our study sample, perhaps due to the younger population (median age 30 years) of TBI patients admitted to our institution during the study period.

In our study, PTH predicted poorer outcome on all measures assessed at the time of rehabilitation discharge. In multivariable analysis, onset of PTH accounted for a 28.9-point reduction out of a maximum possible 126 points in FIM total score at the time of rehabilitation discharge (95\% CI -37.1 to $-20.8, \mathrm{p}<0.001)$. Other predictors of outcome on this measure were better initial clinical status $\left(\mathrm{GCS}_{\mathrm{M}}=6\right.$, following commands), which accounted for an 8.5-point increase in the FIM total score, and longer time from injury to rehabilitation admission, which accounted for a 0.3-point reduction in FIM total score. PTH also independently predicted longer duration of PTA, accounting for a 51.5-day increase in PTA (95\% CI 37.6-65.4, p < $0.001)$.

\section{Role of VP Shunt Timing and Outcome}

Most of the study patients with PTH-52 (88\%)-were treated with CSF diversion via VP shunt prior to discharge from inpatient rehabilitation. Earlier shunting was associated with better outcome by all study measures and predicted better outcome when compared with initial clinical status, age, decompressive intracranial surgery, and presence of intracranial mass effect.

Previous research groups have attempted to assess the role of CSF diversion in PTH outcome. Several studies have assessed outcome and complications in PTH patients with CSF diversion shunting. ${ }^{13,19,22,37}$ One such study found that shunt-treated patients with PTH had longer rehabilitation lengths of stay than those with PTH who did not undergo shunt placement. ${ }^{26}$ A separate report compared outcome in PTH patients who underwent ventriculostomy alone with those who went on to have CSF shunts placed afterward. ${ }^{3}$

To our knowledge, our report is the first to assess the role of the timing of VP shunt placement with respect to outcome in TBI patients. The study found significant associations between earlier shunting and outcome during 
TABLE 7. Comparison of patient characteristics and timing of VP shunt placement

\begin{tabular}{|c|c|c|c|c|}
\hline \multirow[b]{2}{*}{ Characteristic } & \multirow{2}{*}{$\begin{array}{l}\text { All Shunt-Treated Pts } \\
\qquad(\mathrm{n}=52)\end{array}$} & \multicolumn{2}{|c|}{ Time From Injury to VP Shunt Placement } & \multirow[b]{2}{*}{$\mathrm{p}$ Value } \\
\hline & & $\leq 69$ Days $(n=26)$ & $>69$ Days $(n=26)$ & \\
\hline \multicolumn{5}{|l|}{ Demographic characteristics } \\
\hline Age at injury in yrs, median & $24(16-69)$ & $25(16-69)$ & $24(16-66)$ & NS \\
\hline Sex: male & $37(71)$ & $19(73)$ & $18(69)$ & NS \\
\hline TBI etiology & & & & NS \\
\hline Vehicle collision & $34(65)$ & $19(73)$ & $15(58)$ & \\
\hline Sports & $5(10)$ & $1(4)$ & $4(15)$ & \\
\hline Fall & $10(19)$ & $4(15)$ & $6(23)$ & \\
\hline Violence & $2(4)$ & $1(4)$ & $1(4)$ & \\
\hline Other & $1(2)$ & $1(4)$ & $0(0)$ & \\
\hline \multicolumn{5}{|l|}{ Clinical characteristics } \\
\hline $\mathrm{GCS}_{\mathrm{M}}<6$ & $47(90)$ & $22(85)$ & $25(96)$ & NS \\
\hline Acute care LOS in days, median & $70(30-309)$ & $60(30-220)$ & $85(33-309)$ & 0.076 \\
\hline \multicolumn{5}{|l|}{ Ventriculomegaly characteristics* } \\
\hline Preshunting Evans index, median & $0.38(0.25-0.51)$ & $0.43(0.35-0.51)$ & $0.38(0.25-0.47)$ & 0.065 \\
\hline Preshunting Evans index $>0.30$ & $25(93)$ & $6(100)$ & $19(90)$ & NS \\
\hline \multicolumn{5}{|l|}{ Neuroanatomic characteristics of injury } \\
\hline Midline shift or cistern compression & $46(88)$ & $24(92)$ & $22(85)$ & NS \\
\hline Punctate/petechial hemorrhage & $27(52)$ & $12(46)$ & $15(58)$ & NS \\
\hline IVH & $16(31)$ & $7(27)$ & $9(35)$ & NS \\
\hline SAH or subdural fluid collection & $49(94)$ & $25(96)$ & $24(92)$ & NS \\
\hline Epidural hematoma & $11(21)$ & $9(35)$ & $2(8)$ & 0.017 \\
\hline Cortical contusion & $51(98)$ & $25(96)$ & $26(100)$ & NS \\
\hline Subcortical white matter contusion & $16(31)$ & $4(15)$ & $12(46)$ & 0.016 \\
\hline Intraparenchymal bone fragments & $3(6)$ & $2(8)$ & $1(4)$ & NS \\
\hline \multicolumn{5}{|l|}{ Hospital procedures } \\
\hline Shunt placed during rehab & $29(56)$ & $10(38)$ & $19(73)$ & 0.012 \\
\hline Craniotomy & $11(21)$ & $6(23)$ & $5(19)$ & NS \\
\hline Craniectomy & $30(58)$ & $16(61)$ & $14(54)$ & NS \\
\hline Craniotomy or craniectomy & $36(69)$ & $19(73)$ & $17(65)$ & NS \\
\hline
\end{tabular}

rehabilitation, including FIM total scores at admission and discharge, duration of rehabilitation stay, and duration of PTA. This was true for shunting at multiple earlier time points, including within the first 37 days of injury (first quartile of VP shunt placement timing) as well as the first 69 days (median for timing of shunt placement after injury). Furthermore, our study found that earlier placement of VP shunt independently predicted better outcome at the time of rehabilitation discharge, and shorter duration of PTA, when compared with other potential outcome factors.

\section{Interpretation of Results}

The date of VP shunt placement and the time elapsed from TBI to shunting are arguably among the most objective measures used in our subanalysis of PTH patients who underwent CSF diversion. We surmise that the timing of VP shunt placement may be a surrogate for hydrocephalus onset. This is consistent with earlier research comparing mechanisms of TBI injury and timing of subsequent PTH onset. For example, our results demonstrated an association between later VP shunt placement and evidence of subcortical white matter injury. Subcortical contusions were more frequently observed in patients who underwent shunt placement more than 69 days after injury than those shunt treated earlier. This mirrors some previous research findings that suggested that earlier onset of ventricular enlargement is associated with acute SAH or IVH, while onset later in the recovery period is associated more strongly with hypoxic ischemic insult or diffuse axonal injury. ${ }^{29}$ Nonetheless, the temporal association of hydrocephalus onset and VP shunting in our study population is inherently variable. Among $40 \%$ of shunt-treated patients with enlarged ventricles as defined by an Evans index $>0.30$ on preshunting CT scans analyzed in our study, this finding was observed a median of 10 days before VP shunt placement. This suggests that even earlier shunting may have been possible. Shunt placement is based on multifactorial clinical decision making that involves assessment of ven- 


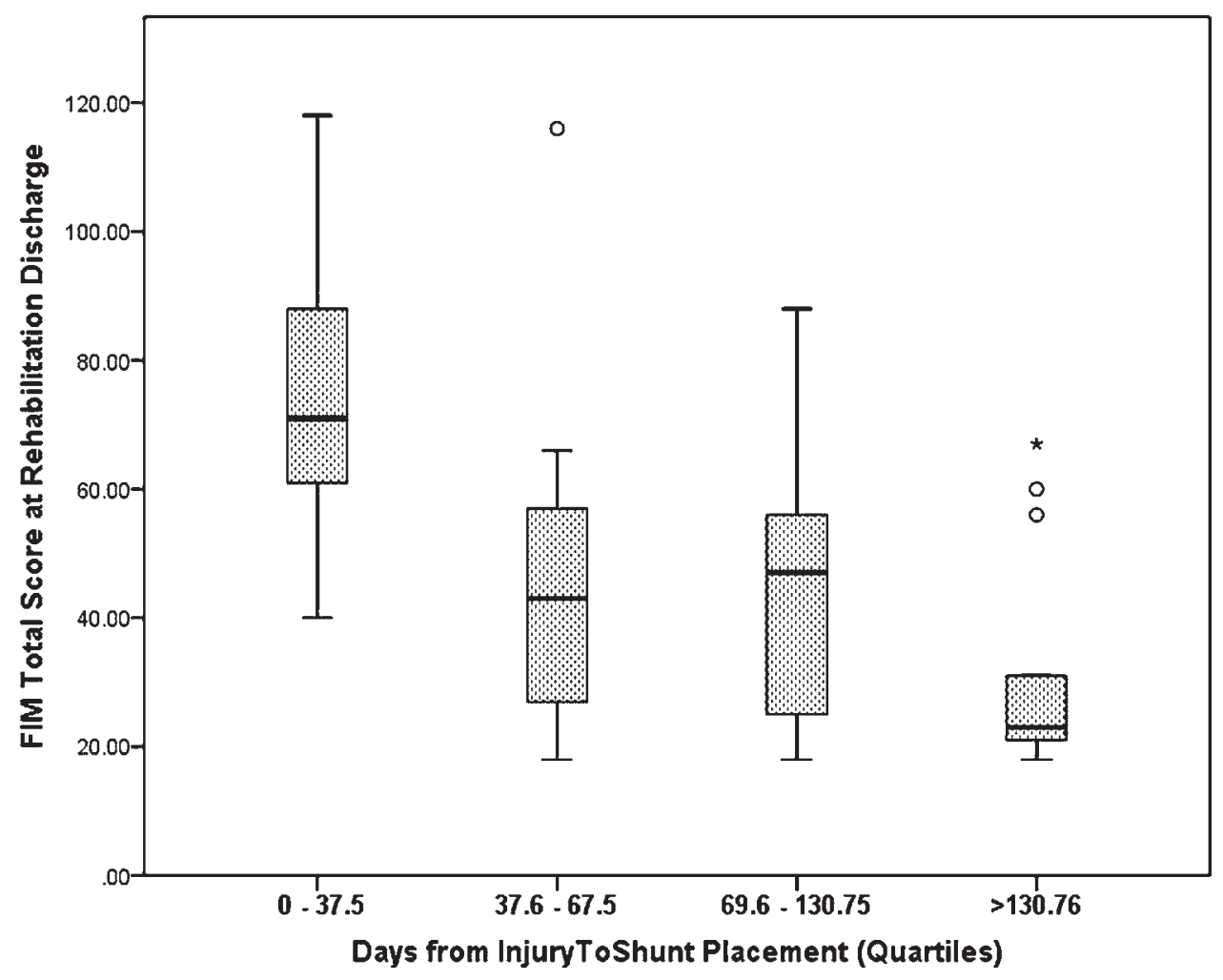

FIG. 1. Comparison of outcome with VP shunt timing. The heavy horizontal line represents the median and the boxes represent the interquartile range (IQR). The whiskers indicate 1 standard deviation, the circles indicate outliers, and the asterisks $\left(^{*}\right)$ indicate extreme outliers.

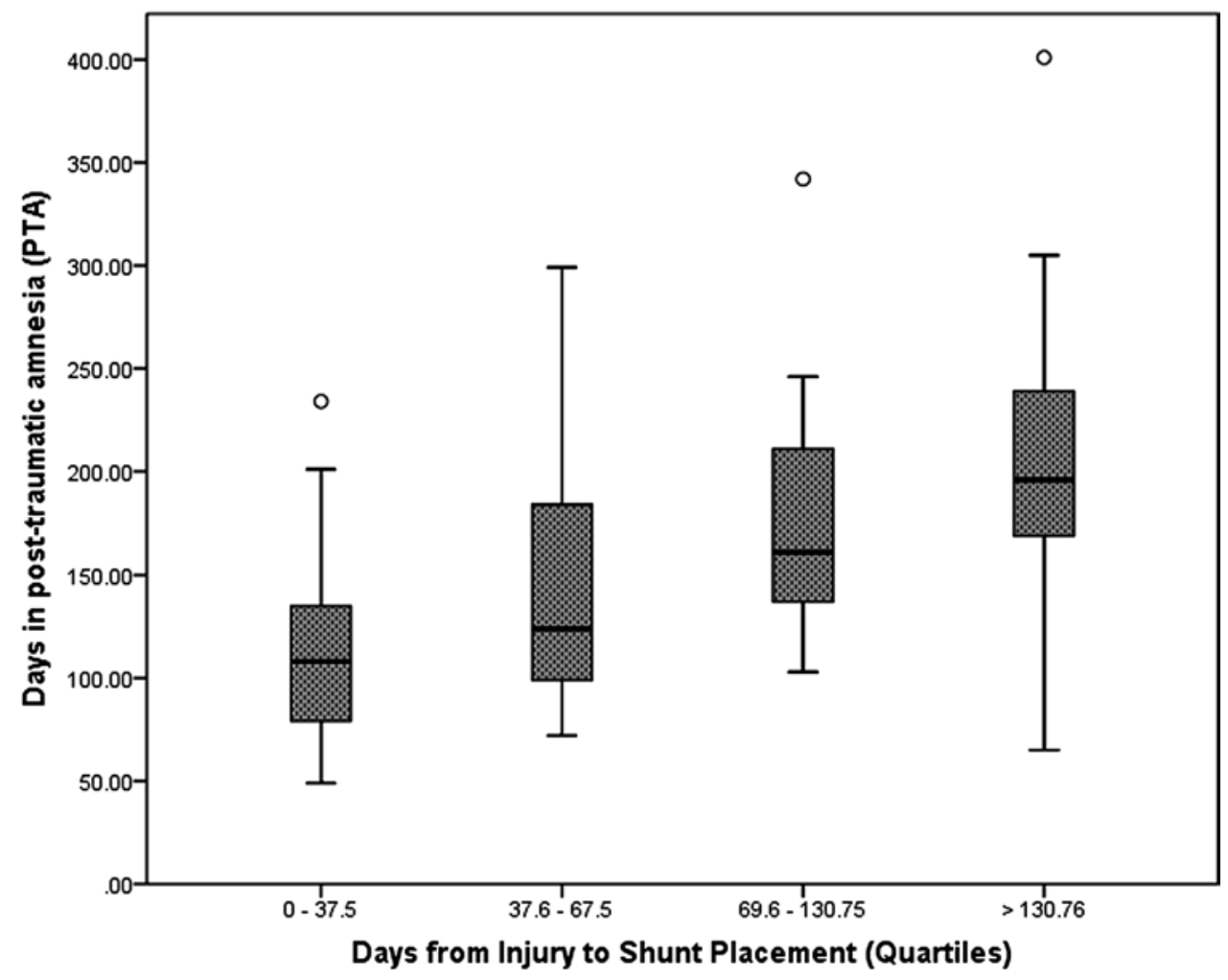

FIG. 2. Duration of PTA and timing of VP shunt placement. The heavy horizontal line represents the median and the boxes represent the interquartile range (IQR). The whiskers indicate 1 standard deviation and the circles indicate outliers. 
TABLE 8. Univariate comparison of outcome and timing of VP shunt placement

\begin{tabular}{|c|c|c|c|}
\hline \multirow[b]{2}{*}{ Outcome Measure } & \multicolumn{2}{|c|}{$\begin{array}{c}\text { Time From Injury to VP } \\
\text { Shunt Placement }\end{array}$} & \multirow[b]{2}{*}{$\begin{array}{c}p \\
\text { Value }\end{array}$} \\
\hline & $\begin{array}{l}\leq 69 \text { Days } \\
(n=26)\end{array}$ & $\begin{array}{l}>69 \text { Days } \\
(n=26)\end{array}$ & \\
\hline \multicolumn{4}{|l|}{ PTA } \\
\hline $\begin{array}{l}\text { Emergence from } \\
\text { PTA, } n(\%)^{*}\end{array}$ & $17(65)$ & $15(58)$ & NS \\
\hline $\begin{array}{l}\text { Duration of PTA in } \\
\text { days } †\end{array}$ & $122(49-299)$ & $179(65-401)$ & 0.001 \\
\hline \multicolumn{4}{|l|}{ Admission FIM } \\
\hline Motor score & $15(13-54)$ & $13(13-45)$ & 0.005 \\
\hline Cognitive score & $7.5(5-22)$ & $5(5-16)$ & 0.084 \\
\hline Total score & $23.5(18-76)$ & $18.5(18-56)$ & 0.018 \\
\hline \multicolumn{4}{|l|}{ Discharge FIM } \\
\hline Motor score & $44.5(13-86)$ & $19.5(13-64)$ & 0.001 \\
\hline Cognitive score & $14.5(5-33)$ & $11(5-25)$ & 0.012 \\
\hline Total score & $59(18-118)$ & $30(18-88)$ & 0.003 \\
\hline \multicolumn{4}{|l|}{$\Delta$ FIM (during rehab) $\ddagger$} \\
\hline Motor score & $+25.5(0$ to +65$)$ & $+6.5(0$ to +46$)$ & 0.005 \\
\hline Cognitive score & $+6.5(0$ to +21$)$ & $+2.5(-3$ to +16$)$ & 0.067 \\
\hline Total score & $+33.5(0$ to +86$)$ & $+11(-3$ to +62$)$ & 0.009 \\
\hline Rehab LOS & $69.5(11-149)$ & $109(10-190)$ & $<0.001$ \\
\hline
\end{tabular}

Data presented as median (range) unless otherwise indicated.

* By time of discharge from inpatient rehabilitation.

$\dagger$ Days from injury to rehabilitation discharge if no emergence from PTA.

$\ddagger$ Change in FIM between rehabilitation admission and discharge.

tricle size and changes in patient clinical status over time. Enlargement of cerebral ventricles is often progressive, occurring over days or weeks following traumatic injury or cranial surgery. Because accompanying changes in clini- cal status frequently are insidious, the exact time of onset of PTH is difficult to identify. Furthermore, it remains difficult to ascertain whether ventricular enlargement is the result of hydrocephalus or parenchymal atrophy that occurs in TBI when axons are damaged, is due to age, or is due to other causes, as many authors have noted. When PTH is suspected, quantifying TBI-associated ventriculomegaly remains controversial. Some research reports have employed the Evans index, ${ }^{7,8}$ which conventionally is applied in normal pressure hydrocephalus, while others have used alternative measurements of ventricular volume, including simple visual inspection on radiography. ${ }^{12,28,40}$ Finally, clinical judgment is inherent in decision making regarding VP shunt placement. Earlier shunting may be correlated to some extent with suspicion of better prognosis. Conversely, it is possible that there may be hesitation to place a shunt in cases of more severe injuries when prognosis appears dire, followed by a decision to treat the patient's hydrocephalus with CSF shunting later in the hospital course if recovery progresses.

\section{Limitations}

The subjective nature of PTH diagnosis and lack of defined evaluation criteria apply to our center as to other institutions. As a result, under- or overestimation of the true incidence of PTH in our study population is possible. Of patients diagnosed with PTH in this study, most (88\%) were treated with CSF diversion by VP shunting prior to discharge from inpatient rehabilitation, as is clinical practice at our institution (Craig Hospital) and acute care facilities where these patients were treated. As such, it was not possible to assess the role of VP shunting versus not shunting in this patient sample.

Because all study subjects were patients admitted to our inpatient rehabilitation hospital, a possible selection bias may have occurred due to admission criteria that perhaps favor individuals with better perceived potential for recovery.

TABLE 9. Predictors of outcome at time of inpatient rehabilitation in 52 PTH patients with VP shunts: results of multivariable logistic regression

\begin{tabular}{|c|c|c|c|c|c|c|}
\hline Outcome \& Predictors & Unstandardized $\beta$ & SE & Standardized $\beta$ & $p$ Value & $95 \% \mathrm{Cl}$ for $\beta$ & Adjusted $\mathrm{R}^{2}$ \\
\hline Rehab discharge FIM total score & & & & & & 0.169 \\
\hline (Constant) & 80.622 & 19.217 & & $<0.001$ & $41.940-119.305$ & \\
\hline $\mathrm{GCS}_{\mathrm{M}}<6$ & -11.199 & 12.361 & -0.120 & 0.370 & -36.081 to 13.683 & \\
\hline Days from injury to shunt placement & -24.165 & 7.275 & -0.439 & 0.002 & -38.809 to -9.520 & \\
\hline Age at injury & -0.419 & 0.241 & -0.228 & 0.089 & -0.905 to 0.066 & \\
\hline Midline shift or cistern compression & 6.347 & 13.190 & 0.074 & 0.633 & -20.204 to 32.898 & \\
\hline Craniotomy or craniectomy & -1.910 & 9.086 & -0.032 & 0.834 & -20.198 to 16.379 & \\
\hline Duration of PTA in days, ${ }^{*}$ all pts & & & & & & 0.220 \\
\hline (Constant) & 70.720 & 53.220 & & 0.190 & -36.406 to 177.847 & \\
\hline $\mathrm{GCS}_{\mathrm{M}}=6$ & -0.875 & 34.233 & -0.003 & 0.980 & -69.783 to 68.033 & \\
\hline Days from injury to shunt placement & 67.707 & 20.149 & 0.453 & 0.002 & 27.150-108.264 & \\
\hline Age at injury & 1.075 & 0.668 & 0.215 & 0.114 & -0.270 to 2.421 & \\
\hline Midline shift or cistern compression & 27.492 & 36.529 & 0.117 & 0.456 & -46.038 to 101.022 & \\
\hline Craniotomy or craniectomy & -0.179 & 25.162 & -0.001 & 0.994 & -50.828 to 50.470 & \\
\hline
\end{tabular}

\footnotetext{
* Days from injury to rehabilitation discharge if no emergence from PTA.
} 
Neuroanatomical characteristics of study patients were derived from neuroimaging obtained in the course of clinical treatment of these patients. Frequency of this imaging may differ between acute and subacute phases of treatment, affecting the consistency of findings between these periods. Furthermore, the Evans index was not calculated for TBI patients who were not diagnosed with $\mathrm{PTH}$, as this was beyond the scope of the present study.

\section{Conclusions}

Posttraumatic hydrocephalus predicts poorer outcome among TBI patients during inpatient rehabilitation, with lower FIM scores at admission and discharge, less FIM improvement, and longer PTA duration. Among patients with PTH, earlier shunting was associated with improved recovery in this study. This timing may reflect earlier onset of PTH, earlier treatment with CSF diversion when PTH is suspected, or a combination of both. These findings suggest that clinical vigilance for PTH onset is warranted after TBI, as is additional study on timing of CSF diversion for these patients.

\section{Acknowledgments}

This work was supported by Craig Hospital; a National Institute on Disability, Independent Living, and Rehabilitation Research (NIDILRR) research grant; and the Rocky Mountain Regional Brain Injury System (grant no. 90DP0034-01-00).

\section{References}

1. Assaf Y, Ben-Sira L, Constantini S, Chang LC, Beni-Adani L: Diffusion tensor imaging in hydrocephalus: initial experience. AJNR Am J Neuroradiol 27:1717-1724, 2006

2. Austin PC: An introduction to propensity score methods for reducing the effects of confounding in observational studies. Multivariate Behav Res 46:399-424, 2011

3. Bauer DF, McGwin G Jr, Melton SM, George RL, Markert JM: Risk factors for conversion to permanent ventricular shunt in patients receiving therapeutic ventriculostomy for traumatic brain injury. Neurosurgery 68:85-88, 2011

4. Bigler ED, Maxwell WL: Neuroimaging and neuropathology of TBI. NeuroRehabilitation 28:63-74, 2011

5. Cardoso ER, Galbraith S: Posttraumatic hydrocephalus-a retrospective review. Surg Neurol 23:261-264, 1985

6. Choi I, Park HK, Chang JC, Cho SJ, Choi SK, Byun BJ: Clinical factors for the development of posttraumatic hydrocephalus after decompressive craniectomy. J Korean Neurosurg Soc 43:227-231, 2008

7. De Bonis P, Mangiola A, Pompucci A, Formisano R, Mattogno P, Anile C: CSF dynamics analysis in patients with post-traumatic ventriculomegaly. Clin Neurol Neurosurg 115:49-53, 2013

8. De Bonis P, Pompucci A, Mangiola A, Rigante L, Anile C: Post-traumatic hydrocephalus after decompressive craniectomy: an underestimated risk factor. J Neurotrauma 27:19651970,2010

9. Denes Z, Barsi P, Szel I, Boros E, Fazekas G: Complication during postacute rehabilitation: patients with posttraumatic hydrocephalus. Int J Rehabil Res 34:222-226, 2011

10. Fleischer AS, Huhn SL, Meislin H: Post-traumatic acute obstructive hydrocephalus. Ann Emerg Med 17:165-167, 1988

11. Guyot LL, Michael DB: Post-traumatic hydrocephalus. Neurol Res 22:25-28, 2000
12. Hawkins TD, Lloyd AD, Fletcher GI, Hanka R: Ventricular size following head injury: a clinico-radiological study. Clin Radiol 27:279-289, 1976

13. Heo J, Park SQ, Cho SJ, Chang JC, Park HK: Evaluation of simultaneous cranioplasty and ventriculoperitoneal shunt procedures. J Neurosurg 121:313-318, 2014

14. Honeybul S, Ho KM: Decompressive craniectomy for severe traumatic brain injury: the relationship between surgical complications and the prediction of an unfavourable outcome. Injury 45:1332-1339, 2014

15. Ishikawa M, Hashimoto M, Kuwana N, Mori E, Miyake H, Wachi A, et al: Guidelines for management of idiopathic normal pressure hydrocephalus. Neurol Med Chir (Tokyo) 48 Suppl:S1-S23, 2008

16. Jackson WT, Novack TA, Dowler RN: Effective serial measurement of cognitive orientation in rehabilitation: the Orientation Log. Arch Phys Med Rehabil 79:718-720, 1998

17. Jiao QF, Liu Z, Li S, Zhou LX, Li SZ, Tian W, et al: Influencing factors for posttraumatic hydrocephalus in patients suffering from severe traumatic brain injuries. Chin J Traumatol 10:159-162, 2007

18. Kammersgaard LP, Linnemann M, Tibæk M: Hydrocephalus following severe traumatic brain injury in adults. Incidence, timing, and clinical predictors during rehabilitation. NeuroRehabilitation 33:473-480, 2013

19. Kwon HG, Jang SH: Cingulum injury by ventriculoperitoneal shunt. Eur Neurol 67:63-64, 2012

20. Landis JR, Koch GG: The measurement of observer agreement for categorical data. Biometrics 33:159-174, 1977

21. Marshall LF, Marshall SB, Klauber MR, van Berkum Clark M, Eisenberg HM, Jane JA, et al: A new classification of head injury based on computerized tomography. J Neurosurg 75 Suppl:S14-S20, 1991

22. Lesniak MS, Clatterbuck RE, Rigamonti D, Williams MA: Low pressure hydrocephalus and ventriculomegaly: hysteresis, non-linear dynamics, and the benefits of CSF diversion. Br J Neurosurg 16:555-561, 2002

23. Levin HS, O'Donnell VM, Grossman RG: The Galveston Orientation and Amnesia Test. A practical scale to assess cognition after head injury. J Nerv Ment Dis 167:675-684, 1979

24. Li G, Wen L, Zhan RY, Shen F, Yang XF, Fu WM: Cranioplasty for patients developing large cranial defects combined with post-traumatic hydrocephalus after head trauma. Brain Inj 22:333-337, 2008

25. Licata C, Cristofori L, Gambin R, Vivenza C, Turazzi S: Post-traumatic hydrocephalus. J Neurosurg Sci 45:141-149, 2001

26. Linnemann M, Tibæk M, Kammersgaard LP: Hydrocephalus during rehabilitation following severe TBI. Relation to recovery, outcome, and length of stay. NeuroRehabilitation 35:755-761, 2014

27. Marmarou A, Foda MA, Bandoh K, Yoshihara M, Yamamoto T, Tsuji O, et al: Posttraumatic ventriculomegaly: hydrocephalus or atrophy? A new approach for diagnosis using CSF dynamics. J Neurosurg 85:1026-1035, 1996

28. Mazzini L, Campini R, Angelino E, Rognone F, Pastore I, Oliveri G: Posttraumatic hydrocephalus: a clinical, neuroradiologic, and neuropsychologic assessment of long-term outcome. Arch Phys Med Rehabil 84:1637-1641, 2003

29. Meyers CA, Levin HS, Eisenberg HM, Guinto FC: Early versus late lateral ventricular enlargement following closed head injury. J Neurol Neurosurg Psychiatry 46:1092-1097, 1983

30. Osuka S, Matsushita A, Yamamoto T, Saotome K, Isobe T, Nagatomo Y, et al: Evaluation of ventriculomegaly using diffusion tensor imaging: correlations with chronic hydrocephalus and atrophy. J Neurosurg 112:832-839, 2010

31. Ottenbacher KJ, Hsu Y, Granger CV, Fiedler RC: The reliability of the functional independence measure: a quantitative review. Arch Phys Med Rehabil 77:1226-1232, 1996 
32. Sim J, Wright CC: The kappa statistic in reliability studies: use, interpretation, and sample size requirements. Phys Ther 85:257-268, 2005

33. Synek V, Reuben JR, Du Boulay GH: Comparing Evans' index and computerized axial tomography in assessing relationship of ventricular size to brain size. Neurology 26:231233, 1976

34. Tarnaris A, Kitchen ND, Watkins LD: Noninvasive biomarkers in normal pressure hydrocephalus: evidence for the role of neuroimaging. J Neurosurg 110:837-851, 2009

35. Tian HL, Xu T, Hu J, Cui YH, Chen H, Zhou LF: Risk factors related to hydrocephalus after traumatic subarachnoid hemorrhage. Surg Neurol 69:241-246, 2008

36. Toma AK, Holl E, Kitchen ND, Watkins LD: Evans' index revisited: the need for an alternative in normal pressure hydrocephalus. Neurosurgery 68:939-944, 2011

37. Tribl G, Oder W: Outcome after shunt implantation in severe head injury with post-traumatic hydrocephalus. Brain Inj 14:345-354, 2000

38. Wagshul ME, Eide PK, Madsen JR: The pulsating brain: a review of experimental and clinical studies of intracranial pulsatility. Fluids Barriers CNS 8:5, 2011

39. Wee HY, Kuo JR: Never neglect the atmospheric pressure effect on a brain with a skull defect. Int Med Case Rep J 7:67-69, 2014

40. Wen L, Wan S, Zhan RY, Li G, Gong JB, Liu WG, et al: Shunt implantation in a special sub-group of post-traumatic hydrocephalus - patients have normal intracranial pressure without clinical representations of hydrocephalus. Brain Inj 23:61-64, 2009

\section{Disclosures}

The authors report no conflict of interest concerning the materials or methods used in this study or the findings specified in this paper.

\section{Author Contributions}

Conception and design: Kowalski, Weintraub, Gerber. Acquisition of data: Kowalski, Weintraub, Gerber, Olsen. Analysis and interpretation of data: Kowalski, Weintraub, Rubin. Drafting the article: Kowalski, Weintraub. Critically revising the article: all authors. Reviewed submitted version of manuscript: all authors. Approved the final version of the manuscript on behalf of all authors: Kowalski. Statistical analysis: Kowalski.

\section{Supplemental Information \\ Online-Only Content}

Supplemental material is available with the online version of the article.

Supplemental Tables. https://thejns.org/doi/suppl/10.3171/2017. 7.JNS17555.

\section{Previous Presentations}

Portions of this work were presented as a platform presentation at the International Brain Injury Association, World Congress on Brain Injury, March 3, 2016, The Hague, Netherlands.

\section{Correspondence}

Robert G. Kowalski: University of Colorado School of Medicine, Aurora, CO. robert.g.kowalski@ucdenver.edu. 